Research Square
Preprints are preliminary reports that have not undergone peer review.

They should not be considered conclusive, used to inform clinical practice, or referenced by the media as validated information.

\title{
Towards Modelling of Evacuation Behavior and Planning for Emergency Logistics Due to the Philippine Taal Volcanic Eruption in 2020
}

\section{Hector Lim}

University of the Philippines Los Banos

Ma. Bernadeth Lim ( $\nabla$ dae032004@yahoo.com)

University of the Philippines Los Banos https://orcid.org/0000-0001-8025-8818

Ann Wendy Rojas

University of the Philippines Los Banos

\section{Research Article}

Keywords: Volcanic evacuation, emergency logistics, evacuation behavior, Taal Volcano

Posted Date: January 3rd, 2022

DOI: https://doi.org/10.21203/rs.3.rs-1178041/v1

License: () (i) This work is licensed under a Creative Commons Attribution 4.0 International License. Read Full License 


\section{Abstract}

Emergency evacuation is the immediate escape of people away from a place of an imminent threat to a place of safety. The ability of the households to evacuate is a crucial component in reducing disaster risk. Logistical issues such as a lack of resources during and after the evacuation, as well as road congestion, might arise, especially in short and no-notice calamities such as a volcanic eruption. This study examines the relationship of variables of evacuation logistics of Barangay Banga, Talisay, Batangas in the context of the 2020 Taal Volcanic eruption. A survey was conducted based on the experience of the households during the volcanic eruption. A descriptive statistical analysis was performed for all the variables on household evacuation logistics to understand the behavior of households as they make decisions during emergencies. These variables include the type of evacuation, departure timing, evacuation mode choice, and destination choice. Additionally, a pairwise correlation was employed to identify the influential factors related to household evacuation logistics such as socio-demographic and household characteristics, hazard-related factors as well as their experience with Taal Volcano's recurring activities. The results of this study aim to provide insights to a better understanding of the evacuation behavior of households in the context of a volcanic eruption and be useful in the evacuation logistics planning of the country.

\section{Introduction}

The occurrence of disasters that are either natural or man-made can cause disruption of human activities and severe damage to infrastructure, livelihood, and loss of lives (Golshani et al. 2019). Geological hazards such as earthquakes, volcanic activities, landslides, and other related geophysical events are examples of natural events. In the case of a volcanic eruption, the activities and effects are not confined to a short period but may also be prolonged depending on the level of intensity of the eruption. In general, small eruptions are more frequent. Conversely, the less frequent the occurrence is the higher probability that the eruption is of high intensity (Barclay et al. 2019). A volcanic eruption is considered major when the Volcanic Explosivity Index (VEI) is greater than or equal to 5. Consequently, the impact of such occurrence is expected to bring massive destruction to the city or region affected, climate disturbances, and has the potential to modify the environment and landscape and human societies (Malawani et al. 2021). In the Philippines, there is a considerable risk in terms of volcanic hazards. The country has 53 volcanoes, 24 of which are active (Smithsonian Institution 2013). Located in the Pacific Ring of Fire where tectonic and seismic activities mostly occur, the country is considered as an area of persistent volcanism (Delos Reyes et al. 2018). Damaging volcanic eruptions were recorded in the past 2,000 years and counting (GFDRR 2020). Large volcanic eruptions of a few active volcanoes such as Pinatubo, Taal, and Mayon caused an impact on human mortality, morbidity, displacement, livelihood, among others. For instance, the eruption of Pinatubo in 1991 and its subsequent impact on the region due to lahar was responsible for at least $26 \%$ of the region's population becoming homeless and $33 \%$ who were affected have evacuated (Witham 2005).

When a disaster occurs, immediate emergency actions are needed to preserve lives, relieve, and control the damage. The support function that guarantees that impacted areas receive emergency resources and rescue services promptly is called emergency logistics (DRC 2008 as cited by Jiang and Yuan 2019). Emergency operations in logistics include facility location, casualty transportation, relief distribution, stock pre-positioning, and evacuation among others. Short-notice evacuation is drafted as one of the main pre-disaster operations which play a significant role in disaster mitigation (Caunhye et al. 2012). During an emergency evacuation, people are removed from a place of an imminent or actual threat to a place of safety. This process involves activities and resources that are crucial to reach a safe area and remain there until it is safe to return, referred to as evacuation logistics (Lindell et al. 2011). In addition to deciding whether to stay or evacuate, the logistics of evacuation is another consideration for households. Considerations on when, and where to evacuate, what means of transportation to use, which route to travel, how long will they stay away, and how much it will cost are the variables in the evacuation logistics (Lindell et al. 2011).

According to the study of Wilson-Goure et al. (2006), the evacuation process is chaotic and disruptive by nature. During a crisis, the expectation is that residents at risk already know if there's a need to evacuate or not. However, they tend to be confused during the actual disaster which resulted in multiple accidents and/or fatalities (Jumadi et al. 2016). People also tend to panic during emergencies that may result in overutilized roads blocking emergency evacuation routes causing severe traffic jams which can also lead to accidents and fatalities (Aalami and Kattan 2017). Severe traffic jams can also happen when car usage exceeds road capacities. For instance, Makinoshima et al. (2017) found that half of the residents used their cars to evacuate during the 2011 Tohoku-Tsunami disaster. This caused severe traffic congestion leading to casualties. In addition to this, there may be $21-25 \%$ of evacuees who take more than one vehicle during hurricane evacuations. In the case of a no-notice evacuation, households only have a limited time to assess the situation and execute the evacuation process. This makes evacuation more difficult to manage. Concerns such as these emphasize the need to understand household evacuation logistics (Wilson-Goure et al. 2006; Wu et al. 2012).

Most literature provides a significant amount of research on the evacuation decision-making of households but there is much less research about issues involved in the logistics of evacuations. Several works of literature have studied the various aspects of evacuation logistics but only a few have looked into it in depth because of its complexity. For instance, most studies found it challenging to identify the relationship of evacuation logistics variables as well as determine any systematic differences in the evacuation logistics in rural and urban areas (Wu et al. 2012). Advance-notice events received much attention in the disaster management literature while no-notice events have not received nearly as much attention, because of a lack of data. During the Taal Volcano's unrest in 1994, the study of Witham (2005) highlights that it is difficult to predict people's movement and behavior during a volcanic crisis. There is a considerable gap in the literature addressing the behavioral analysis of individuals' evacuation decision-making for no-notice emergency events (Golshani et al. 2020). A more complete understanding of the evacuation logistics is crucial for more effective planning and implementation of evacuation as well as reentry operations.

In the 2020 Taal volcanic eruption, the recent study of Prasetyo et al. (2021) has identified several factors affecting the response actions of Filipinos in Luzon, specifically those who lived in Batangas, Manila, and Pampanga. The study shows that evacuation characteristics have high effects on response actions. That is, indicators such as response time, willingness to leave, traffic control, the distance of evacuation centers, and provision of vehicles from the 
government have affected response actions. This study will consider these indicators in understanding the logistics of the household evacuation of Barangay Banga in Talisay, Batangas during the 2020 Taal volcanic eruption. Variables such as departure timing, mode choice, destination choice, travel distance, evacuation duration will be assessed to understand the behavior of households as they make evacuation decisions during emergencies. The results of this study aim to provide insight for a better understanding of household evacuation behavior in the context of a volcanic eruption and be useful in the evacuation logistics planning of the country.

\section{Review Of Related Literature}

Two main actions in disaster response are logistics support and evacuation. Evacuation activities happen during the initial response stage. However, the logistics support activities tend to continue for a longer period to sustain the basic needs of the affected population (Yi and Ozdamar 2007). Evacuation logistics comprises actions and resources required to get to a safe location and remain there until it is safe to return (Lindell et al. 2011; Wu et al. 2012). An assessment of these activities and associated resources are needed to better understand the evacuation logistics of households (Wu et al. 2012). Key behavioral issues related to understanding and predicting evacuation decisions as well as the interrelated steps in the overall evacuation process are important considerations in evacuation planning (Gehlot et al. 2019). A model that emphasizes logistical considerations in evacuation planning such as time and destinations is illustrated in the study of Lim et al. (2013). It integrates models from EMA (2005) and Stepanov and Smith (2009) capturing the essential elements in both models, as shown in Figure 1. For individuals/households, this process indicates their complex decision-making in terms of evacuation during emergencies.

There are usually two phases in the evacuation process: pre-travel and travel phases (Wang et al. 2021). The first phase usually follows a process that includes the detection of all physical and social environment cues and information associated with the hazard. This will eventually lead to making necessary decisions such as the decision to stay or evacuate, and the sheltering choice. In the case of volcanic activity, there are two types of hazards - direct and indirect. Direct hazards include lava flow, ashfall, pyroclastic flow, base surge, gas ejection which can lead to loss of lives, vegetation, crops, infrastructure damage, and effect on the global environment. On the other hand, a lahar is an indirect hazard of a volcanic eruption that can bury lives, houses, infrastructure and cause environmental degradation (World Bank 2005).

People can be affected by volcanic activity in many ways, from ashfall emission hindering daily activities to long-term evacuation. This actual physical evacuation from an area of threat to an area of safety happens in the travel phase and is influenced by several factors. The type and scope of the threat, characteristics of the hazard and the affected area, receipt of authorities notification and information, evacuee behavior, evacuation planning, and execution during an evacuation are some of these influencing factors (Wang et al. 2021). In volcanic unrest, the effects on society can persist for a long time even after the cessation of activity. People may, for example, be displaced in evacuation centers for months after the activity begins, with their houses and livelihoods damaged. Moreover, multiple evacuations can occur from repeated activities of volcanoes (Witham 2015).

\subsection{Evacuation Decision and Type of Evacuation}

Evacuation logistics in the context of a hurricane evacuation have been the subject of many practical and theoretical research and related examinations (Sun and Sun 2020). Social science methodologies in the United States that are well known for this context have been applied in these evacuation studies. Other literature has also focused on tsunami evacuation (Sun and Sun 2020; Sugiarto et al. 2019; Makinoshima et al. 2017). In the context of a volcanic crisis, previous studies of Jumadi et al. $(2016,2017,2018)$ focused on evacuation models and simulations to understand evacuation travel behavior and process.

In a disaster such as a volcanic eruption, the ability of the residents to evacuate is a crucial component in reducing disaster risk (Jumadi et al. 2016). With this, there is also a need to understand the behavioral determinants of the evacuation decision of a household whether to evacuate or not evacuate. Analyzing and identifying these determinants is crucial in the planning and implementation of evacuation, especially in the area of compliance and allocation of resources in an emergency (Lim et. al. 2016).

Past and recent literature on disaster evacuation is mostly centered on evacuation decisions. That is if residents decide to evacuate or not to evacuate, and as to why they decide to stay or leave (Lim et al. 2019; Sarwar et al. 2016; Huang et al. 2016; Medina and Moraca 2016). Further studies included partial household evacuation as another alternative of an evacuation decision, in addition to the traditional binary evacuate/stay decision (Alawadi et al. 2020; Lim et al. 2016). For instance, the study of Alawadi et al. (2020) showed that $47.8 \%$ of the survey respondents indicated that their household chose to stay at home, $10.3 \%$ partially evacuated and $41.9 \%$ have fully evacuated. In the study of Lim et al. (2016), the majority of the respondents have fully evacuated (60.1\%) while households who have not evacuated and partially evacuated accounted for $18.6 \%$ and $21.4 \%$ respectively.

Partial evacuation means some members of the household evacuate while others stay while full evacuation means that all members of the family evacuate (Lim et al. 2016b). The decision to partially evacuate can be due to reasons concerning responsibilities that will be left behind (cited by Perry 1983). Using a multinomial logit model on a post-hurricane survey, Alawadi et al. (2020) identified that partial evacuation is less likely for those who are married. Type of dwelling (mobile, single detached), concerns on injury increases the likelihood of partial evacuation. The total number of evacuees and, the total number of evacuating cars are affected by partial home evacuation decisions. On the other hand, full household evacuation is observed for married residents as well as for older people and families with greater family cohesion (i.e., strong emotional bond). Greater certainty on the impact of the hurricane decreases the likelihood of full evacuation.

To gain better insights on evacuation behavior, the complexity involved in the household level evacuation decision-making process must therefore be understood and addressed (Hasan et al. 2015). Several studies identified several factors that determine an evacuation decision. Wang et al. (2021) broadly differentiated these factors into individual (social and static), environmental, and interventional. At the individual level, the static factors are those that are inherent and do not change over the evacuation process. Examples are socio-demographic parameters like age, race, and gender, as well as socio-economic 
factors like educational attainment, income level, and household characteristics. Hazard knowledge and experience, as well as abilities/impairments of individuals, are personal characteristics that are also included in this category. Lim et al. (2016) identified household characteristics and capacity-related characteristics as influencing factors in a household's decision to evacuate. Factors identified were gender, level of education, number of children in the household, house ownership, housing material, and floor levels, and number of years living in the area. In addition, hazard-related factors such as the source of warning, distance from flood source, and extent of flood damage also influenced this decision. Other literature shows that prior experience with disasters gives people a sense of urgency for an evacuation (Sun and Sun 2020), hence a major contributor to a household evacuation decision (Hill et al. 2021; Sadri et al. 2017). Apart from an individual's static characteristics, the social characteristics were also identified to have an impact in shaping the crowd behavior and other groups in terms of collaboration during emergencies. Impacting factors in this category include their affiliation in a social group (e.g., neighborhood, community groups), as well as the roles/responsibility of an individual that is related to their social identity. According to recent empirical studies, people are more inclined to collaborate with others and engage in situational altruism rather than in mass panic (Wang et al. 2021). This observation was also identified by Jumadi et al. (2017) and Perry (1983) where community and social network influences are identified as factors that affect evacuation decisions. Hence, people are more likely to be influenced by a group or community's actions and decisions rather than with individuals and tend to follow them during emergencies.

Environmental factors such as natural cues/signals also influence evacuation decisions (Wang et al. 2021; Siebeneck and Cova, 2012). Wang et al. (2021) further divided these factors into sensory cues/external stimuli, hazard features (e.g., timing, duration, location, impacting area, etc.), and building/engineering environment (e.g., the layout of the building, geographic location, and features, traffic impediments, etc.). These factors influence evacuation decisions such that when sensory cues or external stimuli are experienced or observed, people tend to take information-seeking actions. Past and recent literature on volcano evacuation identified that the presence of physical evidence is an influencing factor in making an evacuation decision (Perry 1983; Jumadi et al. 2017, 2018). Moreover, an individual's perception of risk is also a critical aspect in the evacuation decision as it influences people's decisions on when to evacuate and when to return home during and after a disaster.

Lastly, interventional factors such as information and actions from disaster response authorities influence the decision to stay or leave (Wang et al. 2021). The recent study of Pan (2020) observed that a local official's order contributed to the decision to evacuate. This is regardless of the presence or absence of probability of information as well as hazard-related information such as information on shelters, evacuation routes. Perry (1983) identified this factor as the second most frequently cited reason for evacuation which reflects the citizen's confidence in officials in times of disasters.

\subsection{Departure Timing}

Once the affected population decides to evacuate, physical evacuation takes place. Subsequent decisions and actions are made based on the interpretations of the environmental factors, situations, and risk perception (Wang et al. 2021). One of which is the household's departure timing defined as the time a household departs during an ongoing threat. Choosing a departure time during a disaster is a complex dynamic process that is influenced by the level of risk posed by the hazard, the characteristics of the household, and the built environment (Hasan et al. 2013). During an evacuation, not all households leave at the same time and the circumstances that account for departure timing vary across incidents (Lindell et al. 2018). The amount of time spent on actions such as planning to evacuate, assembling family members, preparing resources, and actual leaving varies for every household (Sorensen 1991). In general, evacuees collectively tend to leave promptly or more gradually, depending on the perceived urgency of departure, reflecting the time remaining before the anticipated arrival of the hazard event (Lindell et al. 2018). Understanding and anticipating the departure time is a critical behavioral issue in the overall evacuation process, and correct prediction is critical for forecasting evacuation demand over time and developing effective evacuation strategies (Gehlot et al. 2019).

Several studies found that official warnings have both a direct and indirect impact on evacuation decisions (Sorensen 1991; Lindell et al. 2015; Gehlot et al. 2019; Hasan et al. 2013., Huang et al. 2012; Sadri et al. 2013; Wang et al. 2021). In an advanced notice event such as a hurricane, many evacuees immediately leave by the time an evacuation warning is issued. Households who did not get mandatory evacuation orders, on the other hand, were less likely to evacuate (Yin et al. 2014). The study of Sadri et al. (2013) further identified that the source and the timing of evacuation notice is another significant factor that influences not only evacuation decisions but also the evacuation timing of evacuees. For instance, those who received evacuation notices from the media (radio, television, etc.) are more likely to take more than 24 hours to evacuate once they decide to go somewhere safe. Gehlot et al. (2019) also pointed out that older people rely on local television stations for information and are more likely to depart later. Other sources of evacuation alerts such as from social networks (family or friends, neighbors) also result in an early evacuation (less than 6 hours) from a significant portion of individuals.

Other key determinants of this evacuation behavior include socioeconomic factors such as age, income, education level (Hasan et al. 2013; Sadri et al. 2013). Household size is also identified as a significant factor affecting departure timing (Gehlot et al. 2019). Individuals living alone do not require much time to prepare allowing them to depart earlier. The study further identified other significant factors that affect departure timing of households such as evacuation destination and socio-economic characteristics (e.g., age, education, income, race). Evacuees who decide to go to a public shelter are most likely to depart earlier (less than an hour). The same is true for households with low income, and older heads of households who are over 50 years old.

\subsection{Mode Choice}

In any type of disaster, choosing an evacuation mode is an important decision-making activity. There are three different modes of emergency evacuation: vehicular, transit-based, and pedestrian wherein the choice depends on the type of disaster. In real-life situations, some people may decide to evacuate on foot, others would take public transit, while the rest of the evacuees would take personal vehicles (Aalami and Kattan, 2017). Several studies consistently find that the majority of the evacuees chose to evacuate using their vehicle (Lindell et al., 2011, 2015; Makinoshima et al. 2017; Yin et al. 2014). On the other hand, those who do not own a vehicle or choose not to use it rely on their friends/relatives' evacuation vehicles. This sharing of resources and vehicles during evacuation is an important method for increasing critical capacity and enabling a more inclusive disaster response (Borowski 2021). 
The choice of using own vehicle, specifically a car, can be attributed to demographic characteristics such as gender, age, income. Males are more likely to use a car to evacuate than females (Lindell et al. 2011, Makinoshima et al. 2017, Wu et al. 2013, Sugiarto et al. 2019). Also, younger evacuees have a higher likelihood of using a car to evacuate than older evacuees. This is similar to the outcome of Lindell et al. (2011) where lesser probability of using personal vehicles during evacuation is observed in older females. Married evacuees who have larger household sizes, and higher education levels and income were more likely to evacuate using their cars. Concerning economic characteristics, low-income households have a statistically negative association with the motorized transport mode. This suggests that low-income households tend to use non-motorized transport as they may not have any owned motorized vehicle such as a motorcycle or car (Sugiarto et al. 2019).

In the context of tsunami evacuation, Makinoshima et al. (2017) investigated other evacuation mode choice factors such as evacuation destination and distance through a binary logistic regression. The study found out that the most dominant factor affecting mode choice is the evacuation distance. That is, the likelihood of choosing car evacuation was 9.5 times higher for those who traveled long distances as compared to those who traveled shorter distances. Moreover, those who evacuated at a later phase were most likely to have traveled by car than those who evacuated early on. Lindell et al. (2011) also pointed out that households who depend on their friends or neighbors for transportation leave earlier than those taking their vehicles. This contrasts with the findings of Yin et al. (2014) that early departure is more likely for those households who will use their vehicles than those who are relying on a friend/relative's vehicle or a public transit. In addition, public shelters were more attractive to those who took their cars during evacuation.

Reliance on friends or relatives for evacuation transportation might be a major issue for communities that heavily depend on public transportation. In cases like this, communities need to address this by providing public transportation for those in need. Evacuation logistics should consider and incorporate the needs of these carless populations (Lindell et al. 2011). Several factors such as evacuees' socio-demographics, household characteristics, evacuation destination, and prior experience all influence the decision of selecting a mode of transportation (Sadri et al. 2014). In the case of a hypothetical hurricane scenario, the study of Sadri et al. (2014) further identified that higher income is associated with choosing to ride a taxi because they have the financial capacity. It is also found that those who are single are less likely to ride a taxi. The type of accommodation also affects the mode choice. The use of regular bus services is more probable for those who evacuate to a hotel while it is less likely for evacuees to ride with others in going to a public shelter. When evacuating to a public shelter, it is more likely that people will use emergency vehicles provided by emergency management agencies. Lastly, people staying with a friend or relative are less likely to use a special evacuation bus.

\subsection{Evacuation Destination}

Another aspect of evacuation logistics pertains to the evacuation destination choice. Research findings show that the majority of the evacuees choose to stay at the homes of friends and relatives (Mesa-Arango et al. 2013; Wu et al. 2012; Yin et al. 2014, Siebeneck and Cova 2008). This contrasts with the findings of some recent studies (Golshani et al. 2019; Pan 2020; Lim et al. 2021) where most of the evacuees chose to stay in public centers set by the government.

It can be assumed that evacuees would try to go to a closer safe place as much as possible (Cheng et al. 2008). In both advanced notice and no-notice emergencies, households primarily consider an evacuation destination where they have enough information such as distance and the condition of the location (e.g., accommodation, availability of food, etc.). The distance of the shelter affects the timing and mode of transportation to use hence an important consideration for evacuees (Pan 2020). In addition, evacuees also consider the safety and security, medical support, and attributes of communication available in the shelter (cited by Golshani et al. 2019). Other factors that affect a household's decision on where to evacuate include evacuation time, level of trust in authorities, shelter allocation details, modes of evacuation (car-based versus bus-based), and the volume of evacuation traffic (Nagarajan et al. 2021). With evacuation time, a long-distance evacuation tour is more likely to be associated with choosing to stay with family/friends thereby reducing the probability of selecting a public shelter. Similarly, Lindell et al. (2018) pointed out that the increased distance between the evacuees' homes and the shelter, as well as the heightened risk associated with that location, reduced the likelihood of that location being chosen.

A household's level of income also influences this decision. Households with higher income are more likely to stay at a friend or relative's house while those with lower income levels tend to stay at a public shelter. (Wu et al. 2013; Lindell et al. 2011; Mesa-arango et al. 2013; Lim et al. 2021). Because of a lack of resources, lower-income households stay in temporary housing longer than other income groups. Also, the location and construction of their homes are highly vulnerable to the impact of the disaster (Lindell and Prater 2003). Using an evacuation destination logit model, the study of Lim et al. (2021) further identified significant factors related to socio-demographic characteristics. Households with a female head are more likely to choose to evacuate at a relative/friend's house while those who are married are less inclined to stay at their relative/friend's house. Moreover, the number of evacuating household members is another factor such that those with only a few evacuees are more inclined to go to their relative/friend's residence rather than to stay in evacuation centers. Golshani et al. (2019) further identified some hazard-related factors affecting a household's destination choice. These include, among others, the distance between the destination and the threat, the evacuation warning, the destination's vulnerability, and risk perception. Households who have received either mandatory or optional notice to evacuate from government authorities were more likely to go to a public shelter or hotels compared to other destinations (Golshani et al. 2019; Mesa-Arango et al. 2013; Lim et al. 2021). In terms of distance, previous studies of Wu et al. $(2012,2013)$ in the context of a hurricane evacuation showed that public shelter evacuation is also more likely for those who reside farther from the coast. The farther the source of hazard to the place of residence, the more likely it is for residents to seek refuge in public shelters or evacuation centers (Lim et al. 2021). 
Table 1

Summary of findings on some evacuation logistics variables

\begin{tabular}{|c|c|c|c|}
\hline Variable & Study & Hazard & Findings \\
\hline \multirow[t]{4}{*}{$\begin{array}{l}\text { Departure } \\
\text { Timing }\end{array}$} & $\begin{array}{l}\text { Sadri et al. } \\
(2013)\end{array}$ & Hurricane & $\begin{array}{l}\text { - } 73.78 \% \text { of households who received evacuation notice early enough take more than } 7 \text { hours to } \\
\text { evacuate }\end{array}$ \\
\hline & $\begin{array}{l}\text { Gehlot et al. } \\
(2019)\end{array}$ & Hurricane & $\begin{array}{l}\text { - Receipt of mandatory evacuation notice along with sufficient information results to earlier } \\
\text { evacuation }\end{array}$ \\
\hline & $\begin{array}{l}\text { Hasan et al. } \\
(2013)\end{array}$ & Hurricane & $\begin{array}{l}\text { - Receiving evacuation notice either mandatory or optional results in an earlier evacuation than } \\
\text { those who have not received any form of evacuation notice. }\end{array}$ \\
\hline & $\begin{array}{l}\text { Golshani et al. } \\
(2019)\end{array}$ & $\begin{array}{l}\text { No-notice } \\
\text { emergency } \\
\text { event }\end{array}$ & $\begin{array}{l}\text { - } 48 \% \text { immediately leave within the first } 30 \text { min after the occurrence of the disaster; more than } 90 \% \\
\text { would evacuate within } 180 \text { min after the occurrence of the disaster. }\end{array}$ \\
\hline \multirow{5}{*}{$\begin{array}{l}\text { Vehicle } \\
\text { Usage/Mode } \\
\text { Choice }\end{array}$} & $\begin{array}{l}\text { Lindell et al. } \\
(2015)\end{array}$ & Tsunami & - $18 \%$ on foot; $82 \%$ used cars \\
\hline & $\begin{array}{l}\text { Lindell et al. } \\
(2011)\end{array}$ & Hurricane & - $90 \%$ used their vehicles; $9 \%$ rode with friends/relatives; $1 \%$ used public transport \\
\hline & $\begin{array}{l}\text { Makinoshima } \\
\text { et al. (2017) }\end{array}$ & Tsunami & - $1.5 \%$ chose bicycle and motorcycle modes; $50.2 \%$ used cars; $46.9 \%$ walked; $1.5 \%$ others \\
\hline & $\begin{array}{l}\text { Yin et al. } \\
(2014)\end{array}$ & Hurricane & • $73.3 \%$ car; $9.9 \%$ passenger; $16.8 \%$ transit \\
\hline & $\begin{array}{l}\text { Siebeneck and } \\
\text { Cova (2008) }\end{array}$ & Flood & $\cdot 88.8 \%$ personal vehicles \\
\hline \multirow[t]{7}{*}{$\begin{array}{l}\text { Evacuation } \\
\text { Destinations }\end{array}$} & Pan (2020) & Storm Surge & $\begin{array}{l}-61 \% \text { shelters set by the government; } 23.5 \% \text { house of friends or neighbors; } 9.4 \% \text { somewhere else; } \\
5.9 \% \text { hotels }\end{array}$ \\
\hline & $\begin{array}{l}\text { Wu et al. } \\
(2012)\end{array}$ & Hurricane & - $61 \%$ went to friends or relatives; $18 \%$ in hotels/motels; $3 \%$ in public shelters \\
\hline & $\begin{array}{l}\text { Mesa-Arango } \\
\text { et al. (2013) }\end{array}$ & Hurricane & $\begin{array}{l}\text { - } 59 \% \text { evacuated to friends/relative; } 26 \% \text { to hotels; } 9 \% \text { to others; } 3 \% \text { public shelter (or Red Cross } \\
\text { shelter); } 2 \% \text { to workplaces; } 1 \% \text { to church }\end{array}$ \\
\hline & $\begin{array}{l}\text { Lim et al. } \\
(2021)\end{array}$ & Typhoon & $\begin{array}{l}\text { - } 61.24 \% \text { evacuated to public shelter/evacuation center; } 38.76 \% \text { evacuated to family/friends' } \\
\text { house }\end{array}$ \\
\hline & $\begin{array}{l}\text { Yin et al. } \\
\text { (2014) }\end{array}$ & Hurricane & - $67.15 \%$, friend; $24.40 \%$ hotel; $8.45 \%$ shelter \\
\hline & $\begin{array}{l}\text { Golshani et al. } \\
(2019)\end{array}$ & $\begin{array}{l}\text { No notice } \\
\text { emergency }\end{array}$ & $\begin{array}{l}\text { - } 53.54 \% \text { would go to shelters, } 4.17 \% \text { hotels, } 30.42 \% \text { return home; } 11.88 \% \text { would stay with their } \\
\text { family. }\end{array}$ \\
\hline & $\begin{array}{l}\text { Siebeneck and } \\
\text { Cova (2008) }\end{array}$ & Flood & - $60.8 \%$ family, $23.5 \%$ friends, hotel/motel $9.8 \%$ \\
\hline
\end{tabular}

\section{Methodology}

In this section, details presented include that of the study area, processes of data collection, and the modeling framework.

\subsection{Context and Study Area}

Taal Volcano is the second most active volcano in the Philippines. With 35 known eruptions since 3,580 BCE, it is considered one of the world's most deadly volcanoes. The Volcanic Exclusivity Index (VEI) ranges from 1 to 6, with the majority of eruptions falling within the VEI 2 category. (Smithsonian Institution, 2013). One of the worst volcano disasters was the Taal volcanic eruption in 1991 where it killed 1,334 people. Other phreatomagmatic eruptions occurred between 1965 and 1977, causing significant damage and the deaths of roughly 200 persons (Zlotnicki et al. 2018). The eruption of the Taal volcano in 2020 was one of the most recent devastating disasters in the Philippines (Prasetyo et al. 2021). The intense seismic activity affected more than 736,000 people in CALABARZON (Region IV-A), Central Luzon (Region II), and National Capital Region (NCR). People have been displaced, infrastructure and livelihoods have been damaged, and basic services such as water supply and education have been disrupted as a result of the eruption (IFRC 2021). DOST-PHIVOLCS issued an alert level 4 where a precautionary evacuation was ordered over Taal Volcano island and other high-risk communities in Batangas and Cavite provinces (IOM 2020). Public buildings such as schools, covered courts, and public sports centers were utilized as evacuation centers. From the report of the National Disaster Risk Reduction and Management Council (NDRRMC), there were 535 evacuation centers established in Batangas and Cavite supporting roughly 135,610 people $(39,076$ families). Some 170,732 people (44,439 families) stayed outside these registered evacuation centers.

Banga is one of the Barangays in Talisay, Batangas located within the 14-km danger zone. Taal hazard data of PHIVOLCS as of January 2020 showed that Banga is prone to Taal volcano base surge and a small portion (19\%) of the Barangay is prone to Taal volcanic tsunami. According to the 2020 Census, it has a total population of 4,834 residents representing $10.45 \%$ of Talisay's total population. It has 827 households based on the 2015 Census. Situated on the island of Luzon, Banga has an estimated elevation of 17.2 meters (56.4 feet) above mean sea level at coordinates 14.0925, 121.0155 . 
As indicated in Fig. 1, other Municipalities within the 14-km danger zone include the towns of Agoncillo, Alitagtag, Balete, Cuenca, Laurel, Lemery, Lipa City, Malvar, Mataas na kahoy, San Nicolas, Sta. Teresita, Taal, and Tanauan City, all in Batangas; and Tagaytay City in Cavite. After the increasing volcanic activity, the Department of Science and Technology's Philippine Institute of Volcanology and Seismology (DOST- PHIVOLCS) issued an Alert Level from 1 to 4 on January 12, 2020 (IFRC 2020). Local governments within the 14-km extended up to the 20-km radius danger zones were ordered to implement total evacuation.

\subsection{Survey and Data Collection}

The data were collected through a designed survey questionnaire intended for the head of the household, at least 20 years old. These were distributed to the households of Banga, Talisay through the help of the Barangay Health Workers (BHW) on June 28, 2021. The BHWs personally distributed the survey questionnaires within their respective assigned areas and completed the collection in two weeks. It is also important to note that this is conducted during the time of pandemic where health protocols are in place hence face to face interviews are not considered as a feasible data collection method. A total of 418 questionnaires were distributed to the households of Banga but only 368 questionnaires were returned. From this sample, 17 responses had more than $10 \%$ missing data. These observations were removed hence, only 351 questionnaires were returned as usable observations. This represents $42.4 \%$ of the total household size of the Barangay. This also represents those who have evacuated during the Taal Volcano eruption which is relevant to understanding the evacuation logistics of the Barangay.

The survey questionnaire is divided into 5 sections composed of both open-ended and closed-format questions. The survey aims to solicit information based on their actual evacuation experience during the Taal volcanic eruption in 2020. The first section consists of socio-economic and household characteristics such as gender, marital status, education, salary, household size, number of children/senior citizens in the household, vehicle ownership, and the number of years living in the area. The second section measures the threat perception of individuals from the knowledge and information they have with regards to the risk posed by the Taal volcano. The third section captures information regarding their actual evacuation experience during the Taal eruption in 2020.

Questions in this section are meant to elicit evacuation characteristics of households related to variables of evacuation logistics such as departure time, mode choice, evacuation destination. Lastly, comments and suggestions for improvements of future evacuations are indicated in the last section of the survey.

\subsection{Data Analysis}

After the data collection was conducted, the results were automatically encoded. All questions were arranged in columns while all responses were arranged in rows. The researcher checked all online survey results to make sure that all gathered data could be properly utilized for the analysis. Missing information and those who did not evacuate were not included in the analysis.

Statistical methods were employed to identify and analyze the variables that influence the components of evacuation logistics. First, a descriptive analysis was used to describe the quantitatively summarized characteristics of the data set. The study also used correlation analysis to measure the relationship between variables. Correlation between two variables can have a value of -1 to +1 , which quantifies the direction and strength of their linear association. The positive value means that the variables move in the same direction hence, a positive correlation. Conversely, the negative correlation is denoted by a negative value indicating a movement in opposite directions. Values closer to 0 suggest no linear relationship between two variables while values closer to 1 show a strong association.

\section{Results And Discussion}

\subsection{Descriptive Statistics}

Table 2 shows the distribution of household characteristics and related variables collected from 351 observations. These data were collected from the households in Banga, Talisay who have evacuated during the Taal Eruption in 2020. From these households, the majority have evacuated on the day of the eruption (75.8\%) while others evacuated on the next day (24.2\%). With regards to the type of evacuation, results show $78.3 \%$ have fully evacuated while $21.7 \%$ have only partially evacuated. Results also show that the greater part of the evacuees chose to rent an apartment or went to their friends/relatives (76.4\%) while $23.6 \%$ chose to stay at evacuation centers designated by the local government. During the evacuation, half of the evacuees carpooled with their friends and/or relatives' vehicles or rented a vehicle with them. Some of them also used their vehicles (25.9) and the remaining $23.4 \%$ used a vehicle provided by the government. On average, $69.2 \%$ have traveled shorter distances (less than or equal to $25 \mathrm{~km}$ ) while $30.8 \%$ traveled more than $25 \mathrm{~km}$.

Among the respondents, $52.1 \%$ are females and $47.9 \%$ are males, and majorly composed of residents aged 50 above (42.7\%). The married status has the largest distribution among the respondents (71.2\%) while $16.2 \%$ and $12.5 \%$ are single and widow/widowers, respectively. Moreover, a little more than half (52.7\%) are households composed of more than 4 members while the remaining $47.3 \%$ have less than or equal to 4 members in their household. From these households, $55.6 \%$ live with children of utmost 10 years old and $44.4 \%$ have none. Households with no senior citizens accounted for $63.2 \%$ while $36.8 \%$ were living with senior citizens. In terms of income, $52.4 \%$ of the households earn 5,000 or less, while $47.6 \%$ earn more than 5,000 pesos. In addition to this, households who have their vehicle comprise $47.3 \%$ of the total respondents while $52.7 \%$ do not own any vehicle.

The majority of the respondents showed a high-risk perception level which accounted for $64.7 \%$. Two hundred forty-two (68.9\%) received evacuation warnings and notice from 2 or more sources such as government officials/agencies, media, and social media. The remaining 109 respondents (31.1\%) received warnings either from media/social media or from their neighbors. 
Table 2

Descriptive Statistics of Variables

\begin{tabular}{|c|c|c|c|}
\hline Variables & Category & Frequency & Percentage \\
\hline \multirow[t]{2}{*}{ Type of evacuation (NEDEC) } & Partial evacuation & 76 & 21.7 \\
\hline & Full evacuation & 275 & 78.3 \\
\hline \multirow[t]{2}{*}{ Departure Timing (DEP) } & During & 266 & 75.8 \\
\hline & After & 85 & 24.2 \\
\hline \multirow[t]{2}{*}{ Evacuation Destination (DES) } & House of friends or relatives/Rented & 268 & 76.4 \\
\hline & Evacuation center & 83 & 23.6 \\
\hline \multirow[t]{3}{*}{ Mode of Transportation (MODE) } & Commute/Own Vehicle & 91 & 25.9 \\
\hline & Borrowed vehicle/Rented with friends or relatives & 178 & 50.7 \\
\hline & Government vehicle & 82 & 23.4 \\
\hline \multirow[t]{3}{*}{ Position in the Household (POSITION) } & Eldest/alone & 38 & 10.8 \\
\hline & Mother & 157 & 44.7 \\
\hline & Father & 156 & 44.4 \\
\hline \multirow[t]{4}{*}{ Age (AGE) } & $20-30$ & 55 & 15.7 \\
\hline & $31-40$ & 67 & 19.1 \\
\hline & $41-50$ & 79 & 22.5 \\
\hline & $>50$ & 150 & 42.7 \\
\hline \multirow[t]{2}{*}{ Gender (GEN) } & Female & 183 & 52.1 \\
\hline & Male & 168 & 47.9 \\
\hline \multirow[t]{3}{*}{ Civil status of the head of the household (MAR) } & Single/Separated & 57 & 16.2 \\
\hline & Widow/widower & 44 & 12.5 \\
\hline & Married/With Partner & 250 & 71.2 \\
\hline \multirow[t]{3}{*}{ Education (EDUC) } & Primary/Elementary & 68 & 19.4 \\
\hline & Highschool & 238 & 67.8 \\
\hline & Vocational/College & 45 & 12.8 \\
\hline \multirow[t]{2}{*}{ Number of Household Members (MEM) } & $\leq 4$ & 166 & 47.3 \\
\hline & $>4$ & 185 & 52.7 \\
\hline \multirow[t]{2}{*}{ Number of children utmost 10 years of age (ACHILD) } & None (0) & 156 & 44.4 \\
\hline & $\geq 1$ & 195 & 55.6 \\
\hline \multirow[t]{2}{*}{ Number of senior citizens in the family (NSEN) } & None $(0)$ & 222 & 63.2 \\
\hline & $\geq 1$ & 129 & 36.8 \\
\hline \multirow[t]{2}{*}{ Monthly income of the household (INCOME) } & $\leq 5,000$ pesos & 184 & 52.4 \\
\hline & $>5,000$ pesos & 167 & 47.6 \\
\hline \multirow[t]{2}{*}{ Vehicle ownership (OVEH) } & No & 166 & 47.3 \\
\hline & Yes & 185 & 52.7 \\
\hline \multirow[t]{2}{*}{ Number of years living in the area (YLIVE) } & $\leq 10$ years & 65 & 18.5 \\
\hline & More than 10 years & 286 & 81.5 \\
\hline \multirow[t]{2}{*}{ Knowledge on the history of Taal Volcanic eruptions (HIST) } & No & 160 & 45.6 \\
\hline & Yes & 191 & 54.4 \\
\hline \multirow[t]{2}{*}{ Risk Perception (RLEVEL) } & Low to Average & 124 & 35.3 \\
\hline & High & 227 & 64.7 \\
\hline Source of Warning (SWARN) & None/Media \& Social Media/Others & 109 & 31.1 \\
\hline
\end{tabular}

Page $8 / 14$ 


\begin{tabular}{|c|c|c|c|}
\hline Variables & Category & Frequency & Percentage \\
\hline & Government/2 or more sources & 242 & 68.9 \\
\hline \multirow[t]{2}{*}{ Evacuation Distance (DIST) } & $\leq 25 \mathrm{~km}$ & 243 & 69.2 \\
\hline & $>25 \mathrm{~km}$ & 108 & 30.8 \\
\hline \multirow[t]{2}{*}{ Evacuation Duration (DUR) } & $<1$ month & 298 & 84.9 \\
\hline & $\geq 1$ month & 53 & 15.1 \\
\hline
\end{tabular}

\subsection{Variable Correlation}

The summary of correlation results (Table 3) gives information on the effect of each variable individually against other variables. Moreover, the correlation matrix of these variables is used in the analysis of the household's evacuation logistics decision which gives indications of possible predictors of these evacuation decisions.

The intercorrelation of some independent variables is presented in Table 3. For instance, age is negatively correlated with other socio-demographic variables and household characteristics such as education level $(r=-0.271)$, the number of children ( $r=-0.397)$. It has a significant positive correlation with the number of senior citizens in the household $(r=0.270)$ and the number of years living in the residence $(r=0.257)$. In terms of hazard-related characteristics, age has a significant positive correlation with knowledge of previous eruptions of the Taal volcano $(r=0.240)$. This indicates that knowledge of the threat posed by the Taal volcano that usually comes from personal experience and the length of stay in the area can be observed among older people.

The respondent's position in the household is also positively correlated with several demographic variables. A high correlation can be observed with gender $(r=0.753)$ showing that most of the heads of the households are males. A medium positive correlation with marital status ( $r=0.387)$ and a low positive correlation with the presence of children in the household $(r=0.108)$ and vehicle ownership $(r=0.153)$ is also observed. Conversely, there is a significant correlation with the number of senior citizens in the household $(r=-0.190)$. This same relationship can be observed with the education level of the household head where the number of children has a positive correlation $(r=0.110)$ while it has a negative relationship with the number of senior citizens in the household $(r=-121)$. Those who have higher education levels are more likely to have more children but a lesser number of senior citizens in the household. In addition to this, the positive relationship between education level and income level $(r=0.151)$ shows that those who have higher education levels are more likely to have higher income.

Moreover, the number of years living in the residence has a positive correlation with the number of seniors ( $r=0.150)$ while it shows a negative relationship with the number of children $(r=-0.146)$ in the household. That is, those who lived longer in the residence are more likely to have more children and lesser senior citizens in households. 
Table 3

Correlation Matrix of Variables

\begin{tabular}{|c|c|c|c|c|c|c|c|c|c|c|c|c|c|c|c|}
\hline Variables & 1 & 2 & 3 & 4 & 5 & 6 & 7 & 8 & 9 & 10 & 11 & 12 & 13 & 14 & 15 \\
\hline 1. NEDEC & 1 & & & & & & & & & & & & & & \\
\hline 2. DEP & $-.123^{\star}$ & 1 & & & & & & & & & & & & & \\
\hline 3. DES & 0.05 & -0.02 & 1 & & & & & & & & & & & & \\
\hline 4. MODE & 0.05 & $.106^{*}$ & $.345^{\star \star}$ & 1 & & & & & & & & & & & \\
\hline $\begin{array}{l}5 . \\
\text { POSITION }\end{array}$ & 0.09 & 0.04 & 0.03 & -0.09 & 1 & & & & & & & & & & \\
\hline 6. AGE & -0.01 & -0.03 & 0.03 & 0.04 & $.116^{*}$ & 1 & & & & & & & & & \\
\hline 7. GEN & 0.01 & 0.00 & -0.01 & -0.04 & $.753^{* \star}$ & -0.01 & 1 & & & & & & & & \\
\hline 8. MAR & -0.07 & 0.03 & $-.156^{\star *}$ & $-.194^{\star \star}$ & $.387^{\star \star}$ & 0.02 & $.246^{\star \star}$ & 1 & & & & & & & \\
\hline 9. EDUC & -0.01 & 0.01 & -0.04 & -0.06 & -0.06 & $-.271^{\star \star}$ & -0.01 & -0.02 & 1 & & & & & & \\
\hline 10. MEM & -0.07 & 0.03 & -0.04 & 0.05 & 0.03 & 0.07 & 0.05 & 0.09 & -0.03 & 1 & & & & & \\
\hline $\begin{array}{l}11 . \\
\text { ACHILD }\end{array}$ & 0.03 & $.131^{\star}$ & -0.07 & -0.06 & $.108^{\star}$ & $-.397^{\star \star}$ & 0.09 & 0.10 & $.110^{\star}$ & $.129^{\star}$ & 1 & & & & \\
\hline 12. NSEN & $-.231^{\star \star}$ & 0.08 & -0.03 & -0.07 & $-.190^{\star *}$ & $.270^{\star \star}$ & -0.07 & -0.09 & $-.121^{*}$ & 0.04 & -0.08 & 1 & & & \\
\hline $\begin{array}{l}13 . \\
\text { INCOME }\end{array}$ & 0.00 & -0.05 & -0.02 & -0.09 & 0.07 & 0.02 & 0.05 & 0.09 & $.151^{\star \star}$ & 0.03 & -0.07 & -0.03 & 1 & & \\
\hline 14. OVEH & -0.08 & $.123^{\star}$ & $-.158^{\star *}$ & $-.449^{\star *}$ & $.153^{\star \star}$ & 0.04 & $.119^{\star}$ & $.281^{\star *}$ & 0.10 & 0.06 & 0.07 & 0.02 & 0.09 & 1 & \\
\hline 15. YLIVE & 0.00 & -0.07 & $-.114^{\star}$ & -0.08 & 0.00 & $.257^{\star \star}$ & -0.07 & -0.02 & -0.03 & 0.06 & $-.146^{\star *}$ & $.150^{\star *}$ & 0.04 & 0.03 & 1 \\
\hline 16. HIST & -0.06 & 0.01 & -0.02 & -0.10 & 0.09 & $.240^{\star \star}$ & 0.08 & 0.05 & 0.03 & $.107^{\star}$ & $-.105^{\star}$ & 0.09 & -0.06 & 0.10 & $.138^{\star \star}$ \\
\hline $\begin{array}{l}17 . \\
\text { RLEVEL }\end{array}$ & 0.06 & $-.111^{*}$ & -0.01 & -0.10 & 0.05 & -0.07 & 0.08 & 0.00 & 0.05 & 0.00 & -0.05 & -0.04 & 0.06 & -0.10 & 0.06 \\
\hline $\begin{array}{l}18 . \\
\text { SWARN }\end{array}$ & 0.10 & 0.01 & -0.03 & 0.01 & 0.06 & 0.06 & 0.08 & 0.02 & -0.03 & 0.02 & 0.08 & 0.00 & 0.04 & -0.07 & 0.03 \\
\hline 19. DIST & -0.05 & 0.04 & $-.139^{\star *}$ & $-.116^{*}$ & -0.06 & -0.03 & -0.07 & 0.05 & 0.01 & -0.06 & 0.02 & 0.02 & 0.00 & $.149^{\star \star}$ & 0.00 \\
\hline 20. DUR & -0.05 & 0.08 & $-.197^{\star \star}$ & -0.05 & $-.142^{\star \star}$ & -0.03 & $-.213^{\star \star}$ & 0.04 & -0.01 & -0.01 & 0.04 & 0.09 & $-.179^{* *}$ & -0.01 & 0.02 \\
\hline
\end{tabular}

$\star$ Significant at $95 \%$; * Significant at $99 \%$

\subsubsection{Type of Evacuation}

The study reveals that there are two factors that households consider in deciding whether to partially or fully evacuate. The type of evacuation has a significant negative correlation with departure timing $(r=-0.123)$ as well as the number of senior citizens in the family ( $r=-0.231)$. This result suggests that households who decided on a full evacuation are less likely to evacuate late. Moreover, those with more senior citizens in the household tend to evacuate early. This suggests that decision-makers consider the safety of vulnerable groups (e.g., senior citizens) in making evacuation decisions. Furthermore, the decision to leave early can be attributed to a higher perception of risk which results in deciding to leave with the whole family.

\subsubsection{Departure Timing}

Several factors affect the decision of a household in terms of departure timing. Factors that have a significant positive correlation with departure timing include mode of evacuation ( $r=0.106)$, the number of children in the household, and vehicle ownership ( $r=123)$. On the other hand, it is observed that the type of evacuation ( $r=-0.123)$, as well as the risk level $(r=-0.111)$, has a significant correlation with this evacuation decision.

The results show that early departures can be observed for those who willfully evacuate. Moreover, the mode choice having a significant positive correlation with departure timing (Lim et al. 2016b) means those who own a vehicle leave earlier than those who share a ride with friends/relatives. This is because evacuation is easier for those who have their vehicle while those who do not have one take more time to prepare and organize transportation with friends/relatives. Vehicle ownership also influences departure timing as those who do not have vehicles are more likely to leave earlier than those who have a vehicle. This may be because residents who do not have vehicles understand that the longer they stay, the more difficult it becomes to evacuate. This may be because residents who do not have vehicles understand that the longer they stay, the more difficult it becomes to evacuate. Also, it is understood that the longer exposure to volcanic ash, sulfur, and other hazards can pose higher health risks. This also explains the negative relationship of departure timing with risk level which suggests that higher risk perception is associated with an immediate evacuation. This confirms the study of Siebeneck and Cova (2012) stating that risk perception influences the responses of residents to warning notices. This means high-risk perception reduces departure times hence, an early 
evacuation. In other words, those who are risk-averse tend to depart before or during the volcanic eruption. This is consistent with the study of Lim et al. (2016b) in the context of a flood. An early study on evacuation departure timing of Sorensen (1991) suggests otherwise. That is, the level of perceived threat does not result in a quick response from the affected population.

Surprisingly, the presence of more children in the household lowers the likelihood of immediate evacuation which confirms the findings of Hasan et al. (2013) where households with one child will evacuate later than households with no children. This contrasts with previous studies on evacuations (Lim et al. 2013b; Lim et al. 2016) where the greater number of children warrants an immediate evacuation. The reasoning behind this is that households with more children take a longer time to prepare and organize hence will evacuate later.

\subsubsection{Mode Choice}

A household's mode choice during evacuation is affected by some variables related to household characteristics and other evacuation behavior. The results

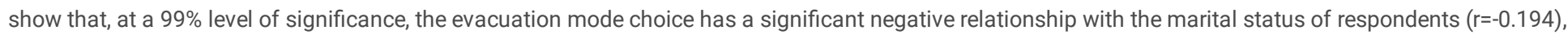
vehicle ownership ( $r=-0.449)$; and evacuation travel distance $(r=-0.116)$ at a $95 \%$ level of significance. On the other hand, there is a significant positive relationship between a household's mode choice and their destination choice $(r=0.345)$ and departure timing $(r=0.106)$.

Marital status influences the mode choice of households. Those who are married are less likely to ride in a government vehicle. Married respondents mainly rely on ridesharing because the majority do not own a vehicle. This is also because there are only a limited number of government-owned emergency vehicles and relying on them would delay their evacuation. On the contrary, the study of Wu et al. (2012) pointed out that married respondents are less likely to share a ride mainly because most of them own a vehicle. Hence, owning a vehicle is another significant factor in a household's evacuation mode choice which is similar to the findings in the study of Lim et al. 2016b.

The departure timing is also an influencing factor in the household's mode choice (Lindell et al. 2011; Lim et al. 2016; Wu et al. 2012). Households who leave early tend to use their vehicle during evacuation. In addition, results also indicate that the type of destination affects mode choice (Lim et al. 2016, Sadri et al. 2014, Wang et al. 2021). Households who will go to evacuation centers/public shelters are less likely to choose ridesharing as a mode choice during evacuation as compared to using a public vehicle. Conversely, those who rode with friends/relatives are more likely to stay at their family/friend's house. This is consistent with the results from the studies of Sadri et al. (2014) and Lim et al. (2016). Lastly, another crucial factor affecting mode choice in evacuation is the distance (Duan et al. 2019). The negative correlation of mode choice with evacuation distance means that those who chose to use their vehicle are more likely to travel long distances during evacuation.

\subsubsection{Destination Choice}

The correlation matrix shows several factors that influence the evacuation destination choice. It shows that the evacuation mode choice ( $r=0.345)$ has a significant positive relationship with the decision. Moreover, variables such as marital status $(r=-0.156)$, ownership of vehicle ( $r=-0.158)$, number of years living in the residence $(r=-0.114)$, distance traveled $(r=-0.139)$ and length of stay in evacuated destinations $(r=-0.197)$ have a significant negative correlation with the choice of evacuation destination.

The results show that different variables affect a household's evacuation destination choice. One variable that significantly increases the likelihood of the household's choice to stay in evacuation is the use of other modes of transportation other than using a personal vehicle. That is, in choosing to stay in evacuation shelters, households are more likely to share rides with friends/relatives, or ride in a government-owned vehicle. While those who own vehicles will most likely evacuate to their friends/relatives or rent apartments/hotels rather than to evacuation centers. Owning a vehicle can be attributed to having a higher income. This economic characteristic is an influencing variable in choosing to evacuate to a family/friends' house (Wu et al. 2013, Lindell et al. 2011, Mesa-arango et al. 2013, Lim et al. 2021). In terms of socio-demographic characteristics, those who are married are less inclined to stay in evacuation centers than those who are single/widow/widower. This result is in contrast with the findings of the study of Lim et al. (2021) where married evacuees are more likely to seek shelter in evacuation centers. This can be related to factors such as lack of knowledge and enough information about evacuation centers such as location, condition of the shelter among others, which is a determining factor in choosing this destination (Pan 2020). Also, it can be observed that the number of years living in the area also affects the destination choice. Those who have lived in their homes for more than 10 years are less likely to choose to stay in evacuation centers. Long-distance travel during evacuation is also associated with the choice of staying with friends/family. This study also supports the findings of Golshani et al. (2019) which identifies that distance is a significant determining factor in choosing an evacuation destination. Lastly, it is also found out that those who stayed longer away from a place of danger were more likely to have stayed at a family/friends' house.

\subsubsection{Evacuation Distance and Duration}

In terms of evacuation distance, the analysis shows that the ownership of a vehicle $(r=0.123)$ and the length of stay away from home $(r=0.130)$ have a low significant positive correlation with the evacuation travel distance, while the evacuation destination shows a significant negative correlation. This suggests that those who own a vehicle are likely to travel farther and would stay longer away from home. This replicates the results in the study of Wu et al. (2012) in the context of a hurricane evacuation. This also indicates that evacuees who will not stay in evacuation centers are more likely to travel shorter distances. Conversely, those who stay with friends/relatives probably have traveled greater evacuation distances.

The amount of time spent away from home is referred to as evacuation duration (Sun and Sun 2020, Wu et al. 2012). For Banga evacuees, the risk perception level $(r=0.105)$ and the distance traveled $(r=0.130)$ have a significant positive correlation with their evacuation duration. This means that those who travelled long distances tend to have a longer evacuation duration. Also, a high level of risk perception contributes to a longer evacuation duration. The study of Calumba et al. (2021) also pointed out that subject perception factors such as disaster risk perception had more impact than socio-demographic factors. However, this study identified some significant socio-demographic factors that affect evacuation duration such as gender $(r=-0.205)$ and income $(r=-0.176)$. Moreover, the choice of evacuation destination $(r=-0.203)$ has a significant positive correlation with this travel behavior. This result implies that households 
with male heads and low income are less likely to stay longer away from the area of danger. They are more likely to go back to their homes earlier than others to check their homes and the livelihood they may have left behind. For the residents of Talisay, growing seedling or sapling, aquafarming, and artificial flower making are their vital sources of income (Talisay Town Profile 2021) and have been significantly disrupted by the volcanic eruption. Moreover, households who chose to go to evacuation centers may have shorter evacuation duration.

\section{Conclusions And Recommendations}

This study employed a statistical analysis of the questionnaire survey results to analyze factors that influence some aspects of evacuation logistics at the Barangay level. The data used in this study was obtained in Banga, Talisay, Batangas, more than a year after the 2020 Taal Volcanic eruption. This paper focused on understanding the logistics of the evacuation behavior of households, involving many variables such as evacuation departure timing, mode choice, evacuation destination, evacuation travel distance, and duration.

The different aspects of evacuation logistics are influenced significantly by several factors. In terms of departure timing, variables such as evacuation mode choice, the number of children in the household, vehicle ownership, and risk level perception influences this decision. Vehicle ownership allows for early departure hence, households who own a vehicle are more likely to leave earlier. The more number of children increases the likelihood of later departure. The reasoning behind this is that households with more children take a longer time to prepare and organize. Conversely, risk level has a negative relationship with departure timing which means that higher risk perception reduces departure timing (i.e., households will leave earlier).

It is observed that around half of the respondents shared a vehicle with friends/relatives while only $26 \%$ used their vehicle. This shows that the majority of the respondents do not own a vehicle and rely on other means of transportation for evacuation. In terms of influencing variables, the results show that sociodemographic characteristics such as marital status and ownership of vehicles are significant factors. These variables have a significant negative relationship with mode choice. That is, those who are married are less likely to ride a government-owned vehicle. Vehicle ownership also affects this decision as households who do not have vehicles mainly rely on shared vehicles with friends/family. Naturally, those who own a personal vehicle will prefer to use their vehicle to evacuate. Some evacuation behavior also affects this decision. Earlier departure is observed with those who have their vehicle than with any other mode of transportation. Furthermore, people who traveled with friends/relatives are more likely to stay at a friend's or family's home.

In terms of evacuation destinations, the results of this study suggest that a friend's or family's home is the most preferred option. This decision is influenced by several factors such as married status, ownership of a vehicle, number of years living in the residence, mode choice, travel distance, and duration. Those who are married are more likely to stay at a friend/family's house. The same goes for households who own a vehicle and who lived in the area for a long time (more than 10 years). Lastly, long-distance travel and duration of evacuation are associated with this destination choice (Golshani et al. 2019).

Another aspect in the evacuation logistics that need to be assessed is the distance traveled by the household going to a safe place and the length of stay in the place. It is identified that those who own a vehicle are likely to travel farther and would stay longer away from home. Moreover, households who will not stay in evacuation centers will most likely travel longer distances. Some demographic factors also affect evacuation duration. For instance, those who have low income, those who travelled long distances tend to have longer evacuation duration and those who stayed in evacuation centers have shorter evacuation duration. This replicates the results in the study of Wu et al. (2012). Lastly, a high level of risk perception also contributes to a longer evacuation duration.

Overall, the residents who evacuated during the Taal volcanic eruption in 2020 lacked prior evacuation experience and knowledge on where to go. Since the last recorded eruption and issued evacuation notice was in 1965, most of the respondents do not have prior knowledge and experience with the effects of the eruption as well as with the evacuation process. As in any other crisis, confusion, and panic during the occurrence of the disaster are some of the constraints on the evacuation process which can result in fatalities (Jumadi et al. 2016). Previous studies show that residents during emergency evacuations are usually not sufficiently instructed, informed, or practically equipped. (Strakova 2016). In a large-scale disaster such as a volcanic eruption, households must know what they should do to prevent any adverse impacts thereof. Moreover, it is imperative for government agencies to carefully plan the logistics during evacuation such as the proper designation of evacuation shelters and routing strategy (Liu and Lim 2016). Reliance on people's initiatives in making these decisions could potentially result in overcrowded evacuation centers and/or severe traffic disruptions. With this, the findings of this study may be valuable to government agencies in further understanding household evacuation logistics. The insights can be useful in evacuation logistics planning such as assigning traffic and road networks, which is important for identifying congestion and delay that might happen during evacuation. By recognizing the evacuation logistics information, the emergency managers could be able to get a clearer picture of how residents organize their evacuation decisions (Wu et al. 2013).

Due to physical constraints from COVID-19 restrictions and the continuous volcanic activities of Taal, data were not collected in other Barangays which were also affected by the 2020 volcanic eruption. Expanding the study area including other Barangays in the Talisay will be useful in understanding the evacuation logistics of the whole Municipality. Furthermore, the logistics of the re-entry operations in this context can also be explored in future studies.

\section{Declarations Funding}

This study was funded by the University of the Philippines System Enhanced Creative Work and Research Grant (ECWRG-2020-226R).

\section{Competing Interests}

All authors declared no relevant financial and non-financial interests to disclose. 


\section{Author Contributions}

Dr. Hector Lim and Dr. Ma Bernadeth Lim contributed to the study conception and survey design. Material preparation and data collection were performed by Dr. Ma Bernadeth Lim and Ann Wendy Rojas. Data analysis were performed by Dr. Hector Lim and Ann Wendy Rojas. The first draft of the manuscript was written by Ann Wendy Rojas and all authors provided feedback on previous versions of the manuscript. All authors read and approved the final manuscript.

\section{References}

1. Aalami S, Kattan L (2017). Fair Dynamic Resource Allocation in Transit-based Evacuation Planning. Transportation Research Procedia, $23,400-419$. https://doi.org/10.1016/j.trpro.2017.05.023

2. Alawadi R, Murray-Tuite P, Marasco D, Ukkusuri S, Ge Y (2020). Determinants of full and partial household evacuation decision-making in Hurricane Matthew. Transportation Research D: Transport and Environment, 83, 102313. https://doi.org/10.1016/j.trd.2020.102313

3. Barclay J, Few R, Armijos MT et al. (2019). Livelihoods, Wellbeing and the Risk to Life During Volcanic Eruptions. Front. Earth Sci. https://doi.org/10.3389/feart.2019.00205

4. Borowski E, Cedillo VL, Stathopoulos A (2021). Dueling emergencies: Flood evacuation ridesharing during the COVID-19. Transportation Research Interdisciplinary Perspectives, 10 (100352). https://doi.org/10.1016/j.trip.2021.100352.

5. Calumba S, Rith M, Fillone AM (2021). Earthquake Evacuation Choice and Management in a Developing Archipelagic Country - A Case of Surigao City, Philippines. Sustainability, 13 (5783). https://doi.org/10.3390/su13115783

6. Caunhye AM, Nie X, Pokharel S (2012). Optimization models in emergency logistics: A literature review. Socio-economic Planning Services, 4-13

7. Cheng G, Wilmot C, Baker J (2008). A destination choice model for hurricane evacuation. Retrieved from https://www.ltrc.Isu.edu/pdf/2008/08-0840.PDF

8. Delos Reyes PJ, Bornas MAV, Dominey-Howes D, et al. (2018). A synthesis and review of historical eruptions at Taal Volcano, Southern Luzon, Philippines. Earth Science Reviews, 177, 565-588. https://doi.org/10.1016/j.earscirev.2017.11.014

9. Duan Z, Xu J, Ru H, Dong Y, Liu X (2019). Analysis of Emergency Evacuation Modal Choice Behavior with Spatial Indicators: Case Study in Xi'an, China. Sustainability, 11, 7023. https://doi:10.3390/su11247023

10. Emergency Management Australia (2005). Evacuation planning. Australian Emergency Manual Series. Manual Number 11.

11. Gehlot H, Sadri AM, Ukkusuri SV (2019). Joint modeling of evacuation departure and travel. Transportation, 46, 2419-2440. https://doi.org/10.1007/s11116-018-9958-4

12. Golshani N, Shabanpour R, Mohammadian A, Auld J, Ley H (2019). Analysis of evacuation destination and departure time choices for no-notice emergency events. Transportmetrica A: Transport Science, 15:2, 896-914. https://doi.org/10.1080/23249935.2018.1546778

13. Golshani N, Shabanpour R, Mohammadian A, Auld J, Ley H (2020). Modeling evacuation demand during no-notice emergency events: Tour formation behavior. Transportation Research Part C: Emerging Technologies, 118(102713). https://doi.org/10.1016/j.trc.2020.102713

14. Jiang Y, Yuan Y (2019). Emergency Logistics in a Large Scale Disaster Context: Achievements and Challenges. International journal of environmental research and public health, 16(5), 779

15. Jumadi. Carver S, Quincey D (2016). A conceptual framework of volcanic evacuation simulation of. Procedia - Social and Behavioral Sciences, 227, 402409. https://doi:10.1016/j.sbspro.2016.06.092

16. Lim H Jr, Lim MB, Piantanakulchai M (2013). A Review of Recent Studies on Flood Evacuation Planning. Journal of the Eastern Asia Society for Transportation Studies, 10, 147-162

17. Lim MB, Lim H Jr, Piantanakulchai M, Uy F (2016). A household-level flood evacuation decision model in Quezon City, Philippines. Nat Hazards, 80, 15391561. https://doi.org/10.1007/s11069-015-2038-6

18. Lim MB, Lim H Jr, Anabo JM (2021). Evacuation destination choice behavior of households in Eastern Samar, Philippines during the 2013 Typhoon Haiyan. International Journal of Disaster Risk Reduction, 56, 102137. https://doi.org/10.1016/j.ijdrr.2021.102137

19. Lindell MK, Kang J, Prater C (2011). The logistics of household hurricane evacuation. Nat Hazards, 58, 1093-1109. https://doi.org/10.1007/s11069-0119715-x

20. Makinoshima F, Abe Y, Machida G, Takeshita, Y (2017). Geosciences, 7(112). https://doi:10.3390/geosciences7040112

21. Malawani MN, Lavigne F, Gomez C, Mutaqin BW, Hadmoko DS (2021). Review of Local and Global Impacts of Volcanic Eruptions and Disaster Management Practices: The Indonesian Example. GeoSciences 11, 109. https://doi.org/ 10.3390/geosciences11030109

22. Pan A (2020). Study on the decision-making behavior of evacuation for coastal residents. International Journal of Disaster Risk Reduction, $45,101522$. https://doi.org/10.1016/j.ijdrr.2020.101522

23. Prasetyo YT, Kurata YB, Acosta AR et al (2021). Factors affecting response actions of the 2020 Taal Volcano eruption among Filipinos in Luzon, Philippines: A structural equation modeling approach. International Journal of Disaster Risk Reduction, 63, 102454.

https://doi.org/10.1016/j.ijdrr.2021.102454

24. Sadri A, Ukkusuri S, Murray-Tuite P, Gladwin H (2014). Analysis of hurricane evacuee mode choice behavior. Transportation Research Part C, $48,37-46$. https://doi.org/10.1016/j.trc.2014.08.008

25. Sarwar M, Anastasopoulos P, Ukkusuri SV, Murray-Tuite P, Mannering FL (2018). A statistical analysis of the dynamics of household hurricane-evacuation decisions. Transportation, 45, 51-70. https://doi.org/10.1007/s11116-016-9722-6 
26. Stepanov A, Smith JM (2009) Multi-objective evacuation routing in transportation networks. European Journal of Operational Research, 198(2), 435446. https://doi.org/10.1016/j.ejor.2008.08.025

27. Straková J, Pártlová P, Váchal J (2016). Logistics Principles for the Emergency Evacuation of People. International Journal of Maritime Science and Technology, 217-222. DOI 10.17818/NM/2016/SI26

28. Sugiarto S, Lulusi , Isya M, Taufik, Haiqal M. (2019). Characterizing mode choice behaviors of the evacuees during emergency evacuation using a Logistic Regression model. IOP Conference Series: Materials Science and Engineering, 523(012032). doi:10.1088/1757-899x/523/1/012032

29. Sun Y, Sun J (2020). Self-assessment of tsunami evacuation logistics: Importance of time and earthquake experience. Transportation Research Part D: Transport and Environment, 87, 102512. https://doi.org/10.1016/j.trd.2020.102512

30. Wilson-Goure S, Houston N, Easton AV (2006). Literature Search Assessment of the State of the Practice and State of the Art in Evacuation Transportation Management. The United States. Federal Highway Administration. https://www.hsdl.org/?view\&did=11252

31. Wu H, Lindell MK, Prater C (2012). Logistics of Hurricane evacuation in Hurricanes Katrina and Rita. Transportation Research Part F, 15(4), $445-461$. https://doi.org/10.1016/j.trf.2012.03.005

32. Yi W, Ozdamar L (2007). A Dynamic Logistics Coordination Model for Evacuation and Support in Disaster Response Activities. European Journal of Operational Research, 179, 1177-1193. https://doi:10.1016/j.ejor.2005.03.077

33. Yin W, Murray-Tuite P, Ukkusuri SV, Gladwin H (2014). An agent-based modeling system for travel demand simulation for hurricane evacuation. Transportation Research Part C: Emerging Technologies, 42, 44-59. https://doi.org/10.1016/j.trc.2014.02.015

34. Zlotnicki J, Sasai Y, Johnston MJS, Fauquet F, Villacorte E, Cordon JM (2018). The 2010 seismovolcanic crisis at Taal Volcano (Philippines). Earth Planets Space 70, 159 https://doi.org/10.1186/s40623-018-0925-2

\section{Figures}

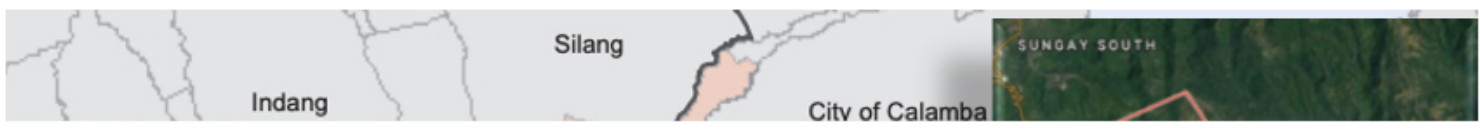

\section{Figure 1}

Taal Volcano 14-km and 17-km radius Danger Zones and Location Map of Banga, Talisay, Batangas

Source: UN OCHA Philippines (2020) and Google Maps (2021) 